\title{
13
}

\section{Wellbeing Literacy and Positive Education}

\author{
Lindsay G. Oades, Lisa M. Baker, Jacqueline J. Francis, \\ and Jessica A. Taylor
}

How can educators best prepare and support students for the twentyfirst century world? Over the past several decades, educators worldwide have targeted a number of capabilities, including knowledge, skills, and behaviours, across learning and teaching domains. A capability may be defined as what we can be and do (Sen, 1993). The development of capabilities has supported student growth in multiple domains, including multimodal literacy, numeracy, information technology, and thinking. Capabilities are inherently future focussed and emphasise potential. These qualities are consistent with the "positive" lens of positive education.

However, it is imperative to ask if significant capabilities have been neglected (Hinchcliffe \& Terzi, 2009). If so, what are they and what benefit can they provide? We suggest that wellbeing literacy (Oades \& Johnston, 2017) is one of those neglected capabilities. As a capability, wellbeing literacy refers to what we can be and do with wellbeing language for the purpose of wellbeing. In this chapter, we first introduce capabilities and consider their pedagogical role within positive education. We define wellbeing literacy, describing its five components. We illustrate what wellbeing literacy looks like in action and why it matters. We then consider implications for educators. As a whole, we suggest that wellbeing literacy may be the tool teachers are seeking to articulate and validate previously disparate wellbeing practices,

L. G. Oades $(\varangle) \cdot$ L. M. Baker · J. J. Francis · J. A. Taylor University of Melbourne, Melbourne, VIC, Australia e-mail: lindsay.oades@unimelb.edu.au 
leading the way to system wide capacity to consistently and intentionally use vocabulary, knowledge, and language skills about and for wellbeing in a manner which is sensitive to the context.

\section{Capabilities as Central to Twenty-First Century Pedagogy}

Teaching is shaped by underpinning pedagogical beliefs. Teaching methods of the twenty-first century combine the wisdom of past philosophers with necessary adaptations for a globalised and complex world. Education facilitates learning about the world, and more importantly, learning how to learn about the world, through building capabilities.

In educational discourse, people often use the terms capability, capacity, competence, skill, and ability interchangeably, however they are distinct concepts (Scheffler, 1985; von Tunzelmann, 2009). Within the context of this chapter, we define a capability as the fluid, dynamic, and interwoven formation of skills, knowledge, opportunities, choices, and behaviours that emerge as a dialectic between a person and the environment (Nussbaum, 2011; Scheffler, 1985; Sen, 1993). For example, Nina wishes to play the piano. If Nina has some ability to play, and the opportunity to play is present, then you could say that Nina has the capability to play the piano. If Nina chooses to play, she has exercised the capability. This is distinctive from a capacity, which is seen as the limit of her ability. A competency is the demonstratable and measurable aspect of one's ability, but unlike the concept of a capability, is silent on whether the opportunity to play a piano is present beyond that situation. Nina has played the piano in the past, and therefore has the demonstrated ability.

Positive education is an adaptation of traditional forms of education focused on building academic competencies, blending the knowledge of wellbeing science with effective pedagogy to promote learning for traditional academic skills, optimal development, and wellbeing (Norrish, Williams, O'Connor, \& Robinson, 2013; Seligman, Ernst, Gillham, Reivich, \& Linkins, 2009). Positive education seeks to develop students' capabilities in wellbeing (defined herein as "feeling good and functioning effectively" (Huppert \& So, 2013, p. 838). From that perspective, then, the key capability that underlies positive education pedagogy is the development of wellbeing literacy. 


\section{Wellbeing Literacy}

Wellbeing literacy has been defined as the capability (incorporating knowledge, vocabulary, language skills) of comprehending and composing wellbeing languages, sensitive to contexts, used intentionally to maintain or improve the wellbeing of oneself or others; in short, mindful language use about and for wellbeing (Oades et al., 2020). Language is central to this definition. Language is a lever for influencing wellbeing as a natural, universal, and constant tool that is never put down (Brothers, 2005; Oades et al., 2020).

It is helpful to note that wellbeing literacy is an umbrella term that encompasses multiple domains of wellbeing. For example, emotional literacy can be conceptualised as existing as a specific area within wellbeing literacy, not as wellbeing literacy itself (Steiner, 2003). Health literacy and mental health literacy similarly are conceptually different from wellbeing literacy; whereas health literacy is intended to improve safety and quality in health (Australian Commission on Safety and Quality in Health Care, 2014) and mental health literacy concerns understanding mental disorder (Jorm et al., 1997), wellbeing literacy is concerned with the flourishing end of the mental health continuum.

Wellbeing literacy is necessary to realise an education system that equally includes the promotion of academic and wellbeing capabilities. Possessing the language, knowledge, and language skills of wellbeing makes it possible to intentionally communicate for the wellbeing of oneself and others. We suggest that individuals, groups, and systems, including those within educational contexts, require this capability to flourish. Further, as later discussed, we consider wellbeing literacy as a fundamental tool to facilitate positive education, including the implementation of positive psychology interventions, providing an integrated model that can enable teachers to integrate wellbeing education with other forms of education.

\section{Wellbeing Literacy as a Capability}

As a capability about and for wellbeing, wellbeing literacy is a relational process between a person and their environment. As evident from the necessary components about and for, wellbeing literacy as a capability model is more than merely a fixed skill, competence, or ability. The term capability is a distinct, dynamic core organising concept, possessing five components that interact between people and their environments to create one's capability (see Table 13.1). Firstly, one must possess vocabulary and knowledge about wellbeing. That is, does the person have one or more words for describing 
Table 13.1 The five components of wellbeing literacy

\begin{tabular}{ll}
\hline Component & Description \\
\hline $\begin{array}{c}\text { Vocabulary and knowledge about } \\
\text { Comprehension of multimodal text related } \\
\text { to wellbeing }\end{array}$ & $\begin{array}{c}\text { Words and basic facts about } \\
\text { wellbeing (i.e. content that is } \\
\text { signified) } \\
\text { Reading, listening, viewing about } \\
\text { and for wellbeing } \\
\text { wellbeing }\end{array}$ \\
$\begin{array}{c}\text { Writing, speaking, creating about } \\
\text { Context awareness and adaptability }\end{array}$ & $\begin{array}{c}\text { awareness of differences across } \\
\text { contexts and adapting the use of } \\
\text { language to fit the relevant context } \\
\text { Intentionality for wellbeing }\end{array}$ \\
$\begin{array}{c}\text { Habit of intentionally using language } \\
\text { to maintain or improve wellbeing } \\
\text { of self or others }\end{array}$ \\
\hline
\end{tabular}

wellbeing that helps them understand the experience? Secondly, one must have comprehension of multimodal texts - the ability to engage with words and knowledge receptively. Third, arising from comprehension is composition-the ability to produce words and knowledge. Fourth, context sensitivity matters-one needs to be able to demonstrate awareness of the contexts within which we use this knowledge, combined with skills to adapt our words for specific contexts. Lastly, actions are intentional —one demonstrates behaviours that embrace choice and intentionality for using these words, skills, and knowledge for the intent of wellbeing for self and others.

Vocabulary and knowledge. Wellbeing vocabulary includes language associated with the wellbeing of oneself and of others. For example, words might include mindfulness, perspective, and belonging. Wellbeing knowledge includes declarative knowledge about wellbeing. For example, a child coming into class after morning break may be able to articulate some words associated with enhanced wellbeing, such as: "the mindfulness corner is comfortable. Mindfulness helps me focus. I feel good when I can focus on my painting".

Multimodal comprehension. Communicating about and for wellbeing, includes both receptive (comprehension) and productive (composition) aspects. Wellbeing literacy reflects a real-world, socially informed view of wellbeing. Comprehension of wellbeing communication occurs through reading, listening, and viewing (Australian Curriculum, Assessment and Reporting Authority [ACARA], 2020a). For example, reading about, or for wellbeing could include reading the novel "Tomorrow When the War Began" by John Marsden in class, and discussing the different perspectives that appear to build student empathy for people who have experienced war. Listening about or for wellbeing could involve intentionally listening to a class playlist to 
boost student and teacher mood. Viewing about or for wellbeing could involve viewing a portrait that generates positive feelings such as awe or inspiration.

Multimodal composition. Beyond receiving wellbeing-related information, communication also includes a productive aspect. Composition of wellbeing occurs through writing, speaking, and creating (ACARA, 2020a). Language is understood here as a socio-cultural phenomenon, which occurs between people (Gee, 1998). Wellbeing experiences are likely composed in congruence with one's socio-cultural values and contexts. Examples of intentionally composing for wellbeing could include writing a letter for a grandparent, who lives some distance away to boost their sense of connection with the family. Speaking for wellbeing, could involve singing your favourite song in the shower, exercising your personal strength of playfulness and boosting positive emotion. Creating about wellbeing could involve choreographing a dance representing the joys and sorrows of life.

Context sensitivity. The meaning of language varies across different times and contexts. For instance, while the word "sick" traditionally refers to being physically unwell, in an online context for Generation Z, it could indicate crazy or cool. Words and communication modes differ across a student's life domains, such as home, school, with grandparents, friends, or work colleagues. Wellbeing literacy requires identifying the context and adapting language use to the context. Sensitivity to context is demonstrated when an individual can use different language and modes to meet the needs and situation of each context. A wellbeing literate person effectively adapts their comprehension and composition of language according to the context, evidencing a form of bilingualism.

Intentionality. Finally, wellbeing literacy requires intentionality (Malle \& Knobe, 1997). Our definition of intentionality is based on Malle and Knobe (1997), involving belief, desire, intention, and awareness. It is purpose driven, with wellbeing as an outcome being the source of that intentionality. Does the sender or receiver of communication aim for wellbeing outcomes? In common language, this could be called the "skillful" or "mindful" use of language. From this perspective, wellbeing literacy assumes that language is non-autonomous. That is, language does not use itself; it has a user within intentions, aware of the contexts within which they are using the language. Like learning a second language, at early stages, use of the language is conscious and energy-ladened, but over time it becomes habitual, such that the non-autonomous use of language naturally occurs, like the fluidity of a bilingual individual. 


\section{The Five Components in Action}

The five-component model of wellbeing literacy is designed to assist people to understand the components of the overall capability and how they are related. A broad overview of the wellbeing literacy model within the school context is shown in Table 13.2, with examples of the capabilities being developed and how the capability might be taught across different ages. To bring this to life, the following vignette illustrates the capability model in action.

Imagine a day within a primary school. The students gather together as the teacher reads a book on mindfulness, asking what the students think mindfulness means. One child responds, "looking at the stars, being quiet". She writes the word "mindfulness" on the whiteboard, and reads: "mindfulness is about connecting with the world around us and the present moment. It helps to balance our minds and our bodies". Students listen, periodically answering questions and sharing ideas. Reading further, the book talks about mindful listening and mindful tasting. The teacher asks, "If we stop and listen now, what do we notice? What can we hear? What is your favourite food? How does it taste? It is hot, salty, sweet, or sour?"

The children move to tables and use art materials to create giant sized cakes and fruit, labelling their work with words about taste, savouring, feeling happy, and being mindful. The teacher encourages the students to place their artwork on display and will use the artwork stimuli for future discussion and writing about ways bodies can be balanced in the present moment and feel well. The teacher also takes photographs of the artwork and sends the photos home with the children, providing a visual reminder for the children to see and reflect upon at home. Then at lunchtime, as the children eat, the teacher roves between small groups and asks, "If you stop and think mindfully, how does your food taste? Is it hot, salty, sweet, or sour? Can you remind yourself to stay in this moment of nourishing your body? How does your body and mind feel after you have eaten?"

Later in the week, other sensory examples of mindfulness are explored, such as touching and smelling. The teacher also introduces a formal practice of mindfulness to the class. The art teacher provides the students with clay and other materials, challenging them to create a sculpture what mindfulness may look like. Music is played at the start of maths to encourage the students to reconnect with their bodies and focus on the present moment and cognitive challenges.

This vignette illustrates that capabilities for and about wellbeing can be built within and through the simultaneous meeting of key curriculum learning requirements. The example could be adapted to the age and stage 


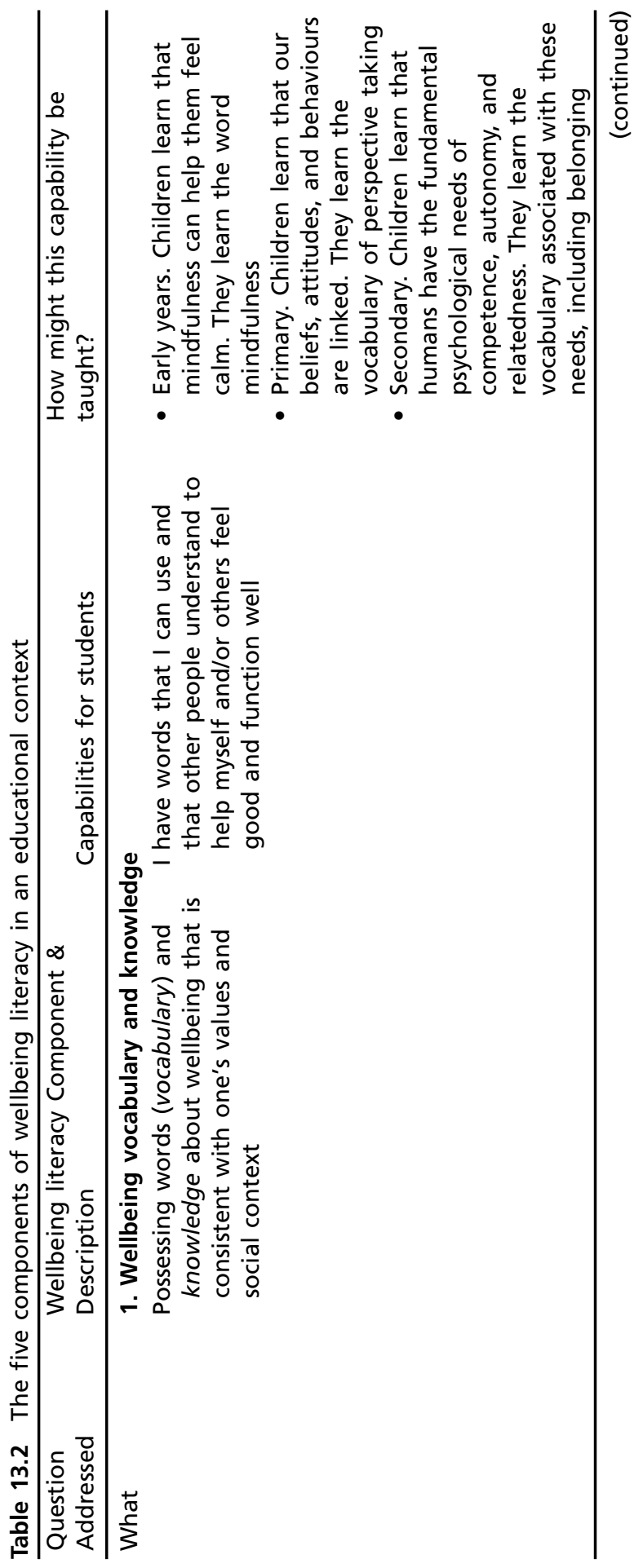




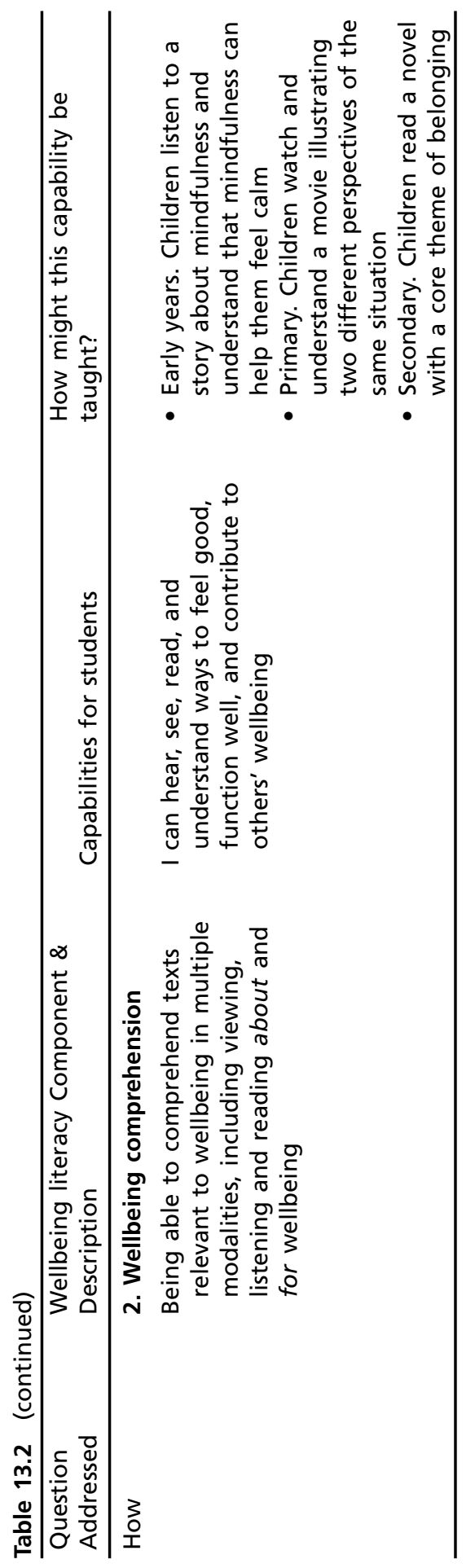




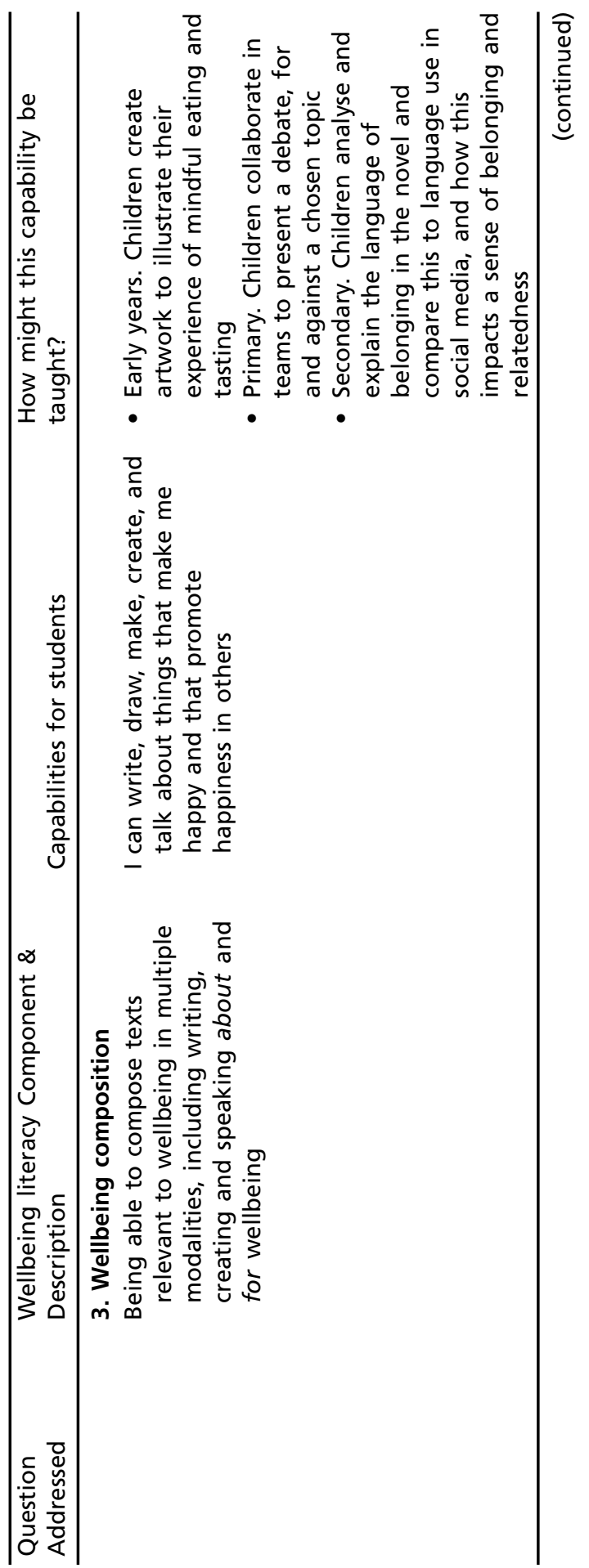




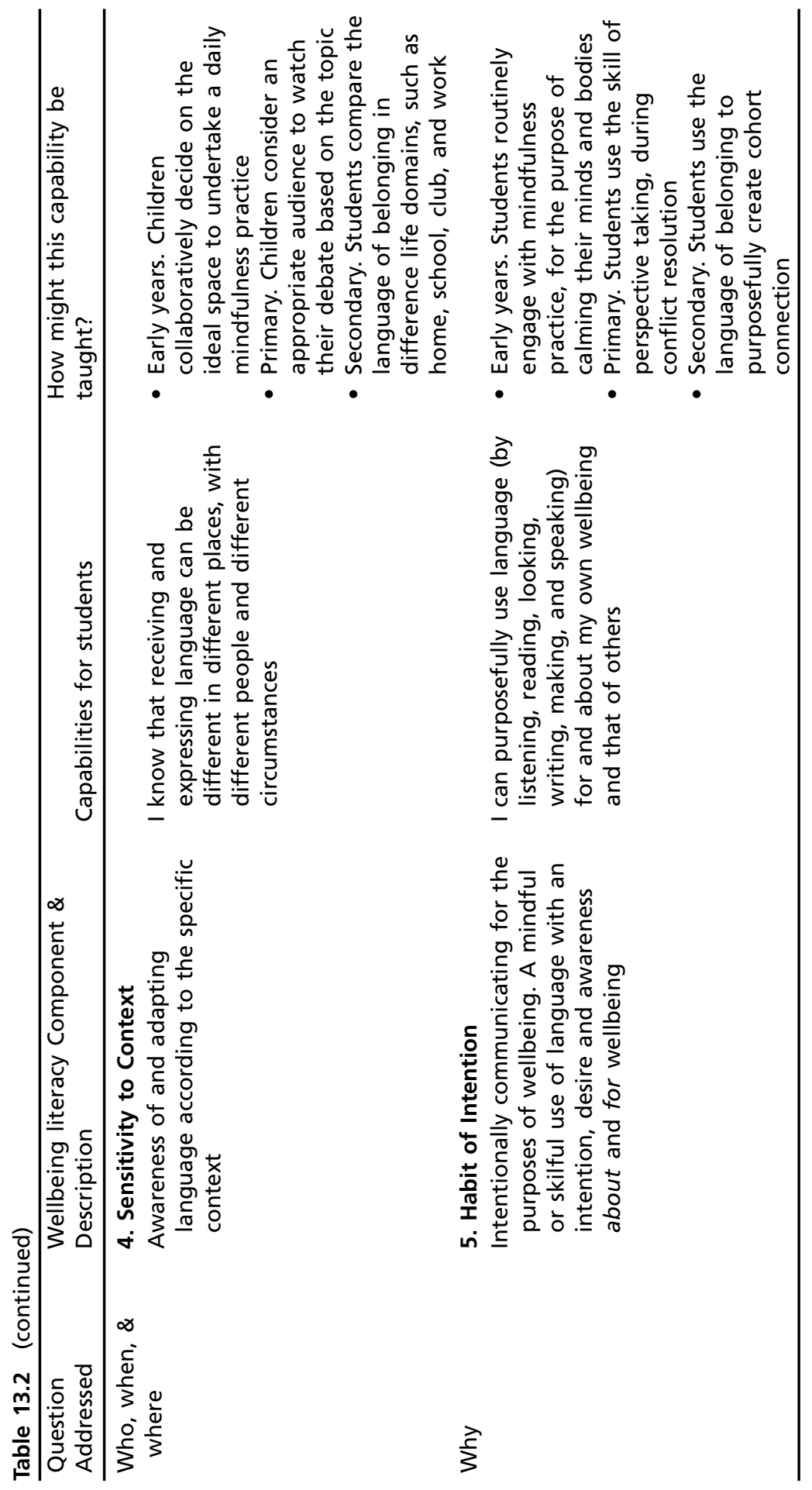


of students. Through these cross-curricular activities and interactions, the teachers in this scenario provided opportunities for students to view, listen, read, write, speak, and create about mindfulness. The term "mindfulness" may not be considered as strictly "wellbeing" by some wellbeing scholars. However, in the context of all five components of wellbeing literacy, if it is used intentionally and in context, it is considered wellbeing literacy. That is, a term gains its meaning within context. Through conversations and experiences regarding nutrition, presence, physicality, senses, and the like, they were teaching students language, knowledge, and skills about wellbeing, for the wellbeing of students, intentionally and with sensitivity to their educational context. The students in turn were developing their own wellbeing literacy as they explored the language, knowledge, and language skills of wellbeing by reading, writing, listening, speaking, creating, and experiencing mindfulness.

\section{Why Does Wellbeing Literacy Matter?}

We suggest that wellbeing literacy is important to positive education practices and future development. Wellbeing literacy suggests a refocus on the intended outcomes of positive education, calling for a need to focus on building student capabilities, rather than focusing on the state or condition of feeling and functioning well. With a natural home in education, it provides an avenue to better integrate positive education within the curriculum, rather than being seen as an added on and separate component. It provides a fundamental tool for incorporating positive psychological practices within the classroom in ways that goes beyond simple activities to impact upon the pedagogy itself, providing a systemic approach to understanding, building, and measuring wellbeing.

First, wellbeing literacy reorients the outcomes that we might be trying to achieve through positive education efforts. Positive education, even in its definition, is about supporting wellbeing. But what does wellbeing mean for the developing young person? If indeed we "treasure" positive education, we must strive to measure it (White \& Kern, 2018). Measurement ensures that targeted constructs are actually fostered (Waters \& Loton, 2019), safeguards legitimacy and evidence base of training and positive psychology interventions (White, 2016), and provides links between wellbeing and academic mastery (Adler \& Seligman, 2016). But what should be measured to support positive education efforts? If the focus is on wellbeing, then evidence around positive education efforts are often minimal at best. Students vary in how they feel and function, as they traverse various social and emotional contexts. 
Rather than focusing on wellbeing per se, wellbeing literacy focuses on the capabilities that will support positive functioning. When students engage in various positive education activities, what did they learn? Do students apply these learnings in the future? What are the mechanisms for change? Wellbeing literacy provides intermediate constructs that might enable or modify how and the extent to which students benefit from various program and activities. Wellbeing literacy is not about a "quick fix" and/or short-term wellbeing gains. Rather, wellbeing literacy is about a sustained shift in language, knowledge, and skills, whereby language use and co-created actions result in sustained wellbeing. Analogous to the well-known proverb, "Give a man(sic) a fish and you feed him for a day; teach him to fish and you feed him for a lifetime", wellbeing literacy feeds for a lifetime (Oades et al., 2020).

Second, wellbeing literacy provides an avenue to integrate positive education into the fabric of the education system. The link between wellbeing and other discipline specific learning and teaching are not always immediately obvious (White \& McCallum, 2020). As wellbeing literacy draws on existing learning and teaching capacities associated with multimodal literacy comprehension and composition (ACARA, 2020a), providing language and approaches that educators are already familiar with. Wellbeing literacy learning and teaching can occur while simultaneously addressing existing curriculum requirements (ACARA, 2020a, b). As such, wellbeing literacy re-positions positive education as a purposeful and effective direction for wellbeing education that can be integrated with already over-crowded curricula, making it more likely for educators to prioritise and integrate wellbeing. We argue that by weaving wellbeing literacy into the fabric of education, positive education may become more broadly accessible, acceptable, and sustainable at multiple system levels (i.e., student, parents, teachers, wider community, and governing bodies). Synergistic "buy-in" to positive education across these levels and thus sustained practice may be better achieved through the shared understandings and practices achieved through wellbeing literacy.

Third, wellbeing literacy supports systems-informed approaches to education (Allison, Waters, \& Kern, 2020; Kern et al., 2020). Positive psychology has been criticised for overemphasising the individual within its approaches and interventions (Kern et al., 2020). Positive education similarly often fails to view wellbeing as a complex and adaptive system that goes beyond the individual student. Education comprises a variety of systems. Individual students are nested within multiple school systems, including teacher/student, student/student, student/parent, parent/teacher systems. These micro-systems are nested within larger school systems, such as parent/teacher/student. These interrelated parts and systems are necessarily 
mediated by language. Individual wellbeing, systemic wellbeing, and language are thus inseparable and interdependent. Wellbeing literacy helps us use language to traverse all dimensions of wellbeing, as educators and students interact with language itself, and with each other. This language system can help generate wellbeing for the entire system.

As a language system, wellbeing literacy supports the repositioning and reframing of communication interactions within education, becoming a systemic approach to understanding, building, and generating wellbeing. More effective and sustained learning for and about wellbeing can be realised through an understanding of these language systems. A systems conceptualisation of wellbeing via wellbeing literacy also allows for "unintended wellbeing" literacy consequences (Hieronymi, 2013). Students have individual levels of, and approaches to, wellbeing and wellbeing literacy, as do teachers and parents. Previously unobserved, emergent benefits from wellbeing conversations had between students, teachers and parents (Oades et al., 2020) are visible through a wellbeing literacy model.

\section{Implications for Educators}

We have proposed wellbeing literacy as a capability for students and as a language system and key to positive education. However, educators may ask, so what? What impact, effective, useful or not, does wellbeing literacy have on daily practice or pedagogy? Can it help students? Can it help me? These questions are rightly expressed by those at the "coal face" of education.

Whether it is a new concept or one that immediately feels known, from our experience, wellbeing literacy resonates with teachers. Languishing students are not uncommon in classrooms, and teachers and educators ardently seek student wellbeing (White, 2016). The Australian Report of the Organisation for Economic Co-operation and Development (OECD) Teaching and Learning International Survey (2018) records $99 \%$ of teachers believe student wellbeing to be important (White \& McCallum, 2020). However, while teachers are passionate about their students and vocation, teaching is complicated and practitioners require answers and pragmatism (Allen, Rowan, \& Singh, 2019; Fried, 2001).

Teachers are crucial for wellbeing science and contemporary positive education practices, such as wellbeing literacy, to be successfully applied within education systems. Wellbeing literacy must not only engage educators, but also be practical, comprehensible, and does not add to an already crowded curriculum and workload. With these factors in mind, we suggest that wellbeing literacy offers a measurement tool, a frame for educational practices, a 
conduit for positive education, and a language system for students, teachers, and families.

\section{Wellbeing Literacy Offers a Measurement Tool}

As discussed, wellbeing literacy offers the potential for capturing the true ingredients of positive education practices, rather than wellbeing outcomes that may or may not be detectable. Ongoing and rigorous assessment of wellbeing programs is the key for the longevity of positive education (Seligman \& Adler, 2018; Waters \& Loton, 2019). Additionally, educators pursue evaluation of the effectiveness of pedagogical and wellbeing practices. Teachers need to know what outcomes are expected and if they are being reached. A teacher-friendly, testable model of student wellbeing, such as the wellbeing literacy model, is the next logical step for positive education and teacher practice (Waters \& Loton, 2019). Notably, while work is still developing in this area, wellbeing literacy potentially can be assessed via self-report measures such as the Wellbeing Literacy 6-item Self Report Scale (Oades et al., 2020) or via tracking the acquisition of skills (representing latent wellbeing literacy through developmental stages).

\section{Wellbeing Literacy as a Frame for Educational Practices}

Positive educational practices are growing globally and rapidly (Rusk \& Waters, 2013; Seligman \& Adler, 2018), offering a broad terrain of programs and curricula for schools and educators to consider. However, conceptualisations of wellbeing lack clarity in schools and policy, leading to fragmentation and inconsistent implementation (Thomas, Graham, Powell, \& Fitzgerald, 2016). Context, time, relevance, efficacy, and practicality need to be weighed by busy educators. Ad hoc, one-off, inconsistent, and/or disconnected programs and activities might be enthusiastically or involuntarily added on to curriculum, resulting in a variety of fads, rather than a sustainable integrated approach to positive education. Despite efforts being well meant, ineffective or harmful effects can thus result (White, 2016; White \& Kern, 2018; White \& Murray, 2015).

Wellbeing literacy, as a model of capability provides a frame for teachers to view and deliver existing and/or new positive education practices. The meta-construct of wellbeing literacy offers teachers a structure or lens through which to select, convey, and connect specific activities. Previous disparate practices, such as gratitude journaling in English, breathing exercises in physical education, reflective self-portraits in art, charity collections, and buddy 
activities can be connected as comprehension and composition of wellbeing capabilities. Existing "caught" and "taught" curriculum of various labels (pastoral care, social and emotional learning, character education, relationships, personal identity, and positive education) that may not be formally linked to discrete curriculum outcomes, can be woven together under the higher order frame of wellbeing literacy capabilities. Overall, this can provide a frame for embedding a focus on wellbeing within schools.

\section{Wellbeing Literacy as a Conduit for Positive Education}

For positive education to "stick" (White, 2016) teachers need reassurance that positive education activities are working. But improvements in wellbeing (or the lack thereof) often occur within a black box, unclear why some students benefit while others do not, and whether any gains might be due to specific activities or not. Oades (2017) argues wellbeing literacy is an essential conduit between wellbeing education and student learning outcomes. Insight on wellbeing gains is possible when students are viewed as developing a capability and intentionality, language skills, and knowledge related to wellbeing that enable them to continue to improve wellbeing over time. Instead of an external intervention being "done" to students (Oades \& Johnston, 2017), capability is built, and students are more likely to remain engaged.

\section{Wellbeing Literacy as a Language System}

As argued, positive psychology, with extensions to positive education, requires a systems approach and interconnected view for effectiveness, sustainability, and longevity (Kern et al., 2020). Teachers understand the inseparable and interdependent relationships within their school system, primarily as a nest or triad of student, teacher, and parent (or family). Student wellbeing is vital to all parties in the triad; however, communication about this complex and intangible construct can be challenging. Wellbeing literacy offers an intelligible bridge for teachers to involve and inform parents about wellbeing and positive education through the familiar and tangible reference of literacy. With age and meta-cognitive abilities, older students can conceptualise and value their own capabilities in communication for and about wellbeing. An educator's task is arguably easier when all parties share a common language and expectation for wellbeing in education practice and pedagogy. Advantages exist for students (and teachers) when parents can speak "the language of 
schooling" (Clinton, Hattie, \& Dixon, 2007, p. 19) and parental expectations and ambitions for their child are both shared and realistic.

\section{Conclusion}

Education has long been concerned with developing the distinct capacities of individuals (Dewey, 1916). Positive education's growth-based emphasis is compatible with this notion of building capability. Wellbeing literacy is focused on building wellbeing capabilities and teaching rather than treating to proactively build student's capability to flourish. With challenges to sustaining positive education efforts, we suggest that the focus within education systems should be on building wellbeing literacy, rather than wellbeing per se. We must teach, rather than treat, for flourishing. Twenty-first century learning and learners requires multi-literate, multimodal, and inclusive wellbeing education. Educators and education systems need to know how wellbeing learning is enabled, measured, and sustained. The 5-component model of wellbeing literacy offers a language system for positive education practices and interventions, fostering personalised, collective, and systemic approaches to creating the conditions for students to flourish. Wellbeing literacy potentially teaches people the vocabulary, knowledge, and skills to positively affect their own wellbeing, as well as the wellbeing of others. Wellbeing literacy is thus vital to positive education as a fundamental tool, an integrated model, and a sustainable and measurable view of wellbeing.

The role of educators is central to this. Educators discern, deliver, and evaluate positive education-related practices daily. Wellbeing literacy offers educators a tool for framing those practices, creating connection across otherwise disconnected components. Within the necessarily interconnected system of education, wellbeing literacy also provides a bridge between students, educators, and families, helping all to share the language of wellbeing education and school. Capabilities framed and articulated by educators, shared by families, and embedded in students, hold promise for sustainable growth. This overarching wellbeing literacy goal of capability building is well positioned in the pedagogical hands of educators.

\section{References}

Adler, A., \& Seligman, M. E. P. (2016). Using wellbeing for public policy: Theory, measurement, and recommendations. International Journal of Wellbeing, 6(1). http://doi.org/10.5502/ijw.v6i1.429. 
Allen, J., Rowan, L., \& Singh, P. (2019). Status of the teaching professionAttracting and retaining teachers. Asia-Pacific Journal of Teacher Education, 47(2), 99-102. https://doi.org/10.1080/1359866X.2019.1581422.

Allison, L., Waters, L., \& Kern, M. L. (2020). Flourishing classrooms: Applying a systems-informed approach to positive education. Contemporary School Psychology. https://doi.org/10.1007/s40688-019-00267-8.

Australian Commission on Safety and Quality in Health Care. (2014). Health literacy: Taking action to improve safety and quality. Sydney: ACSQHC. https://www.safetyandquality.gov.au/sites/default/files/migrated/Hea lth-Literacy-Taking-action-to-improve-safety-and-quality.pdf.

Australian Curriculum, Assessment and Reporting Authority (ACARA). (2020a, June 16). Literacy. https://www.australiancurriculum.edu.au/f-10-curriculum/eng lish/.

Australian Curriculum, Assessment and Reporting Authority (ACARA). (2020b, June 16). General capabilities. https://www.australiancurriculum.edu.au/f-10-cur riculum/general-capabilities/.

Brothers, C. (2005). Language and the pursuit of happiness: A new foundation for designing your life, your relationships \& your results. Naples, FL: New Possibilities Press.

Clinton, J., Hattie, J., \& Dixon, R. (2007). Evaluation of the Flaxmere Project: When families learn the language of school. Wellington, NZ: Ministry of Education.

Dewey, J., (1916). Democracy and education: An introduction to the philosophy of education.

Fraillon, J. (2004, June 16). Measuring student well-being in the context of Australian schooling: Discussion Paper. Australian Council for Education Research. https:// research.acer.edu.au/well_being/8/.

Fried, R. L. (2001). The passionate teacher: A practical guide. Beacon Press.

Gee, J. P. (1998). What is literacy? In V. Zamel \& R. Spack (Eds.), Negotiating academic literacies: Teaching and learning across languages and cultures (pp. 18-25). Mahwah: Lawrence Erlbaum.

Hieronymi, A. (2013). Understanding systems science: A visual and integrative approach. Systems Research, 30, 580-595. https://doi.org/10.1002/sres.2215.

Hinchcliffe, G., \& Terzi, L. (2009). Introduction to the special issue 'capabilities and education'. Studies in Philosophy and Education, 28(5), 387-390. https://doi. org/10.1007/s11217-009-9133-7.

Huppert, F. A., \& So, T. T. C. (2013). Flourishing across Europe: Application of a new conceptual framework for defining well-being. Social Indicators Research, 110(3), 837-861. https://doi.org/10.1007/s11205-011-9966-7.

Jorm, A. F., Korten, A. E., Jacomb, P. A., Christensen, H., Rodgers, B., \& Pollitt, P. (1997). "Mental health literacy": A survey of the public's ability to recognise mental disorders and their beliefs about the effectiveness of treatment. Medical Journal of Australia, 166 (4), 182-186. https://doi.org/10.5694/j.13265377.1997.tb140071.x. 
Kern, M. L., Williams, P., Spong, C., Colla, R., Sharma, K., Downie, A., Taylor, J. A., Sharp, S., Siokou, C., \& Oades, L. G. (2020). Systems informed positive psychology. Journal of Positive Psychology, 15, 705-715. https://doi.org/10.1080/ 17439760.2019 .1639799$.

Malle, B. F., \& Knobe, J. (1997). The folk concept of intentionality. Journal of Experimental and Social Psychology, 33, 101-121. https://doi.org/10.1006/jesp. 1996.1314.

Norrish, J. M., Williams, P., O'Connor, M., \& Robinson, J. (2013). An applied framework for positive education. International Journal of Wellbeing, 3(2), 147161. https://doi.org/10.5502/ijw.v3i2.2.

Nussbaum, M. C. (2011). Creating capabilities: The human development approach. Cambridge, MA: Harvard University Press.

Oades, L. G. (2017). Wellbeing literacy: The missing link in positive education. In M. A. White, G. R. Slemp, \& A. S. Murray (Eds.), Future directions in well-being: Education, organizations and policy (pp. 169-173). Cham: Springer International Publishing.

Oades, L. G., \& Johnston, A. L. (2017). Wellbeing literacy: The necessary ingredient in positive education. Psychology Behavioural Science International Journal, 3(5), 1-3.

Oades, L. G., Ozturk, C., Hanchao, H., \& Slemp, G. (2020). Wellbeing literacy: A language-use capability relevant to wellbeing outcomes of positive psychology interventions. The Journal of Positive Psychology, 15(5), 696-700. https://doi.org/ 10.1080/17439760.2020.1789711.

OECD. (2019). PISA 2018 results (Volume III): What school life means for students' lives. OECD Publishing, Paris. https://doi.org/10.1787/acd78851-en.

Rusk, R. D., \& Waters, L. E. (2013). Tracing the size, reach, impact, and breadth of positive psychology. The Journal of Positive Psychology, 8(3), 207-221. https:// doi.org/10.1080/17439760.2013.777766.

Scheffler, I. (1985). Of human potential: An essay in the philosophy of education. Oxon: Routledge.

Seligman, M. E. P., \& Adler, A. (2018, June 16). Positive education. In Global happiness policy report 2018 (pp. 52-74). Global Happiness Council. http://www. happinesscouncil.org/.

Seligman, M. E. P., Ernst, R. M., Gillham, J., Reivich, K., \& Linkins, M. (2009). Positive education: Positive psychology and classroom interventions. Oxford Review of Education, 35(3), 293-311. https://doi.org/10.1080/030549809029 34563.

Sen, A. K. (1993). Capability and wellbeing. In M. C. Nussbaum \& A. K. Sen (Eds.), The quality of life (pp. 30-53). Oxford, UK: Clarendon Press.

Steiner, C. (2003). Emotional literacy: Intelligence with a heart. Berkeley, CA: Personhood press.

Thomas, N., Graham, A., Powell, M. A., \& Fitzgerald, R. (2016). Conceptualisations of children's wellbeing at school: The contribution of recognition theory. Childhood, 23(4), 506-520. https://doi.org/10.1177/0907568215622802. 
von Tunzelmann, N. (2009). Competencies versus capabilities: A reassessment. Economia Politica, 26(3), 435-464.

Waters, L., \& Loton, D. (2019). SEARCH: A meta-framework and review of the field of positive education. International Journal of Applied Positive Psychology, 4(1-2), 1-46. https://doi.org/10.1007/s41042-019-00017-4.

White, M. A. (2016). Why won't it stick? Positive psychology and positive education. Psychology of Well-Being, 6(1), 2. https://doi.org/10.1186/s13612-0160039-1.

White, M. A., \& Kern, M. L. (2018). Positive education: Learning and teaching for wellbeing and academic mastery. International Journal of Wellbeing, 8(1), 1-17.

White, M. A., \& McCallum, F. (2020). Responding to teacher quality through an evidence-informed wellbeing framework for initial teacher education. In J. Fox, C. Alexander, \& T. Aspland (Eds.), Teacher education in globalised times (pp. 115-137). Singapore: Springer Singapore. https://doi.org/10.1007/978-98115-4124-7_7.

White, M. A., \& Murray, S. (2015). Building a positive institution. In M. A. White \& S. Murray, (Eds.), Evidence based approaches in positive education: Implementing a strategic framework for well-being in schools. New York, NY: Springer Press. https://doi.org/10.5502/ijw.v8i1.588.

Open Access This chapter is licensed under the terms of the Creative Commons Attribution 4.0 International License (http://creativecommons.org/licenses/by/4.0/), which permits use, sharing, adaptation, distribution and reproduction in any medium or format, as long as you give appropriate credit to the original author(s) and the source, provide a link to the Creative Commons license and indicate if changes were made.

The images or other third party material in this chapter are included in the chapter's Creative Commons license, unless indicated otherwise in a credit line to the material. If material is not included in the chapter's Creative Commons license and your intended use is not permitted by statutory regulation or exceeds the permitted use, you will need to obtain permission directly from the copyright holder.

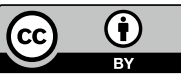

